Theories \& Applications, the International Edition

Printed Version: (ISSN 2090-5262)

Online Version: (ISSN 2090-5270)

March 2012, Volume 2, No. 1 Pages (45 - 56)

\title{
The Effect of Years of Practice on Some Postural Deviations in Foil Fencers
}

\author{
Zakaria Ahmed El-Sayed*, Yasser Mohammed Hagger**
}

\begin{abstract}
:
The study aims at identifying the effect of years of practice on some of the postural deviations in foil fencers. The survey-based descriptive method was used being suitable for this type of study. The research sample was randomly selected from the foil fencers in different Egypt clubs (Alexandria Weapon Club - Alexandria Sporting Club - Egyptian Weapon Club - Police Club MubarakCenter). The sample consisted of 170 foil fencers of different stages, enrolled in the Egyptian Union of Weapon, with periods of practice of 6 months at least. The pilot study was conducted in Alexandria Weapon Club, while the basic study was conducted in a number of Egyptian clubs in Cairo and Alexandria. The main conclusions were: (1) Years of practice have a significant effect on the degree of wry neck deformities, scoliosis and bow leggedness - genu varum; (2) Practicing foil fencing causes the measured degree of the low shoulders deformity to come closer to the correct degree which is 140 degrees, thus improving the deformity; (3) There is a direct correlation between the degree of deformities of wry neck, scoliosis and low shoulders and years of practice; (4) Gaining weight leads to bow leggedness deformities. The study recommends: (1) Posture measurements should be taken and medical examination should be conducted when selecting foil fencing beginners, so that the selection is based on scientific rules; (2) A protocol should be developed by foil fencing clubs nationwide, based on the conclusions made reached in this study, according to which an examination is conducted on fencers at specified intervals to identify the posture deviations that may occur, and the increase or decrease in these deviations; (3) Foil fencing coaches should be made aware of the need for training fencers in a scientific manner so that practitioners can be protected against postural deviations which are on the rise increasing according to results of this study. While due care is given to the working muscles, other muscles should not be neglected in training all through the years of training; (4) Studies similar to this study should be made on the three other types of fencing and also on other sporting activities in general.
\end{abstract}

\section{Problem of the study and its importance:}

Sport performance is a dynamic expression of the human body. The differences in the shape of the body are closely related to sport activity requirements (25:17). Studying posture indicates the importance of the general condition of persons, because posture is of great importance to a person's health and hence the safety and health of the community in general and athletes in particular, (26:2).

\footnotetext{
* Lecturer, Biological Science and Sport Health Department, Faculty of Physical Education, Abu Qir, Alexandria University, Egypt.

** Lecturer, Combats and Individual Sports Department, Faculty of Physical Education, Abu Qir, Alexandria University, Egypt.
}

Good posture exists when parts of the body are well - linked together in such a manner as to create balance in the body movements. The skeletal and muscular systems are responsible for this balance (13:178). The upright posture of a person body is the position which achieves balance between the muscular strength of the body and gravity, and where the arrangement of bones and muscles is in the normal position, so that the body's normal curvatures are well in place, so that man con do his/her daily work and all the movements needed without feeling tired and with minimal effort (6:9).

Each sport has its own competitive character which is different from that of other sports, and each has its own postural deviations (11:179). A postural deviation is defined as a deviation or 
change in the shape of an organ or part of an organ of the body from the normal condition, resulting in a change in the relationship between this organ and other organs (17:149).

Any increase or decrease in the body's normal curvatures is, therefore, an indicator of poor posture expressed in lack of balance (6:9). Occupation-related habits that involve using one side of the body are among the causes of postural deviations, especially when they tend to place the load of the body weight on that particular side of the body for long periods (16:153). In this regard, the nature of the performance in foil fencing which is practiced in a relatively small arena, and which depends on fast movements while keeping en garde throughout the duel, requires facing the opponent in a side-stepping position and using the hand holding the weapon $(7: 35)(3)$.

Foil fencing is one of the individual sports that require a great effort from the player, and involve several physical, tactical and physiological requirements which aim at protecting the player against injury and help $\mathrm{him} /$ her acquire a balanced posture so as to achieve higher levels $(1: 35-37)(4)$. The en garde position taken by the foil fencer for long periods during training and matches, focusing on the balance, and repeating the performance of moving forwards and backwards, and thrusting by side - stepping lead to some postural deviations (11:179)(3). Foil fencing is one of the sports that develop certain muscles of the body, making them stronger than the muscles of the other side as a result of practicing for extended periods of training, and weakening the unused side resulting in unbalance in foil fencer's movements as a result of some postural deviations $(9: 261)(8: 22)$. Thus, the researchers indicate that the progress in the sports level in general, and in foil fencing in particular, can be achieved by taking into account the basic principles derived from theories and scientific laws associated with the activity of the human body to provide the capacity sufficient for education and training based on science. This is only possible when state-of-the-art techniques are used in training to reduce the risk of injury.

A pilot study was therefore conducted to identify a number of the common posture deviations in foil fencers. The study was conducted in the period $25-29 / 09 / 2009$ in Alexandria Weapon Club on 20 foil fencers under 20 years old, with the aim of identifying the effect of practice on posture deviations. Table 1 shows the results of the study

Table (1)

\begin{tabular}{|c|c|c|c|c|c|c|c|c|}
\hline $\begin{array}{c}\text { posture } \\
\text { deviations }\end{array}$ & wry neck & $\begin{array}{c}\text { Low } \\
\text { Shoulders }\end{array}$ & $\begin{array}{c}\text { Round } \\
\text { shoulders }\end{array}$ & $\begin{array}{c}\text { Thoracic } \\
\text { kyphosis }\end{array}$ & Scoliosis & $\begin{array}{c}\text { knock } \\
\text { knees }\end{array}$ & $\begin{array}{c}\text { Bow } \\
\text { leggedness }\end{array}$ & Flat foot \\
\hline $\begin{array}{c}\text { Number of } \\
\text { Foil } \\
\text { fencers }\end{array}$ & 12 & 12 & 8 & 5 & 16 & 7 & 14 & 8 \\
\hline
\end{tabular}

Table (1) shows that wry neck, low shoulders, scoliosis and bow leggedness are the commonest deviations. They counted for more than $50 \%$ of the sample population. This is consistent with the results reached by Ibrahim Nabil(1), indicating the commonest posture deviations in Egyptian foil fencers. Despite the great advances in the methods of training in all sports, the results reached by Ibrahim Nabil's study in 1973 still agree with the conclusions of the pilot study conducted by the authors of this paper (2009). These were the question underlying this study: did the years of practice affect the amount of common deviations incurred by foil fencers? Did they cause these deviations to increase, decrease or disappear?
Did this happen as a result of training the working muscles, as well as the opposite muscles? Previous studies on the subjects only focused on defining the common posture deviations referring to percentages. The effect of years of practice on deviations has not been subject of studies reviewed by authors of this paper. This is the rational of this present study.

\section{Objective of the Research:}

Identifying the effect of years of practice on some of the posture deviations suffered by foil fencers 


\section{Hypotheses:}

1. Years of practice have an effect on some postural deviations in foil fencers.

2. There are significant differences between years of practice and postural deviations in foil fencers.

3. There is a correlation between years of practice and postural deviations in foil fencers.

\section{Previous studies:}

Ibrahim Nabil (1): This study aimed at identifying the common postural deformities of weapon players. The sample consisted of 200 foil fencers. According to the study, the commonest deformities among foil fencers were low shoulders, followed by Scoliosis, then Bow leggedness. These accounted for the highest percentages of deformities. The author recommended paying more attention to compensatory exercises.

Wael Omar (25): This study aimed at identifying the common postural deformities in certain sports (wrestling - Basketball Volleyball - hockey). The sample consisted of 325 players. The study revealed a high prevalence of postural deviations. The author recommended making early examination of postural deviations that may appear in early stages.

Mahrosa Ali Hassan \& Mervat Youssef (11): This was a study of postural deviations in female foil fencers and basketball players. The sample consisted of 102 players (22 foil fencers - 80 basketball players). According to the study, the highest percentages of postural deviations in female basketball players were low shoulders and round shoulders, while the deviations in female foil fencers were concentrated in low shoulders and Scoliosis. Training programs that include compensatory exercises were recommended to prevent postural deviations.

Osama Ahmed Ismail (19): This study aimed at identifying and developing a therapeutic program of spinal deviations of foil fencers under. The sample consisted of 54 players. Results showed that spinal postural deviations occur in foil fencers and that the therapeutic program suggested in the study had a positive effect on correcting the spinal deviations.
Metzing Miklos (12) suggested stretching exercises and studied their effect on spinal deviations in foil fencers. The sample consisted of 40 male/female athletes who practiced foil fencing for 14-16 years. According to the study, the suggested stretching program had a significant effect on improving spinal deviations in foil fencers, and compensatory exercises increased the foil fencers' efficiency.

\section{Comment on previous studies:}

Previous studies indicate the prevalence of postural deviations in some sports in general and in foil fencing in particular. Studies focusing on foil fencing covered certain aspects of postural deviation from authors' points of view. Building on the results of such studies, the current study also took into consideration the findings of the pilot study conducted by the authors with the aim of tracking the effect of years of practice on those deviations. In addition, the current study used accurate and up to date means of measuring to determine the exact degree of every deviation in all subjects of the sample.

\section{Procedures:}

\section{Methodology:}

The survey-based descriptive method was used being suitable for this type of study.

\section{Research Scope:}

\section{Human Scope:}

The sample was selected randomly from Egyptian foil fencers in different clubs (Alexandria Weapon Club - Alexandria Sporting Club - Egyptian Weapon Club - Police Club - MubarakCenter). The total sample consisted of 170 foil fencers of different stages, enrolled in the Egyptian Weapons Federation, with no less than 6 months of practice. They were divided as follows:

1. The basic sample consisted of 150 foil fencers, divided into five the different stages of practicing years assigned for the study. Each stage was represented by 30 foil fencers. 
2. The pilot study sample consisted of 20 foil Table (2) shows the Statistical description of the fencers, not included in the basic sample. sample (foil fencers) in the key variables: age, Duration of the practice was over 5 years. height and weight.

Table (2)

Statistical description of the sample (foil fencers)

in key variables (age, height and weight) $(N=150)$

\begin{tabular}{|l|c|c|c|c|c|c|c|c|}
\hline $\begin{array}{l}\text { Statistical } \\
\text { treattments } \\
\text { Variables }\end{array}$ & $\begin{array}{c}\text { Lowest } \\
\text { value }\end{array}$ & $\begin{array}{c}\text { Highest } \\
\text { value }\end{array}$ & Range & Mean & $\begin{array}{c}\text { Standard } \\
\text { deviation }\end{array}$ & Median & $\begin{array}{c}\text { Skweness } \\
\text { coefficient }\end{array}$ & $\begin{array}{c}\text { Coefficient } \\
\text { of } \\
\text { variations }\end{array}$ \\
\hline Age & 12 & 20 & 8 & 16.30 & 2.52 & 16.60 & $0.36-$ & 19.10 \\
\hline Height & 131 & 185 & 54 & 167.48 & 12.24 & 170 & $0.62-$ & 9.79 \\
\hline Weight & 30 & 85 & 55 & 57.35 & 10.97 & 60 & $0.72-$ & 24.88 \\
\hline
\end{tabular}

Table (2) shows that skweness coefficient the sample. Table (3) shows the statistical values of the key variables (age, height and description of the research groups of foil fencers weight) fell within ( \pm 3 ). This confirms the fact in key variables (age, height and weight), by that the sample was free from immoderate years of practice. distributions defects, and reflects moderation of

Table (3)

Statistical description of the research groups of foil fencers in key variables: age, height and weight by years of practice

\begin{tabular}{|c|c|c|c|c|c|c|c|c|c|}
\hline \multicolumn{2}{|c|}{$\begin{array}{c}\text { Statistical } \\
\text { treatments } \\
\text { Years } \\
\text { of practice }\end{array}$} & \multirow{2}{*}{$\begin{array}{c}\text { Lowest } \\
\text { value }\end{array}$} & \multirow{2}{*}{$\begin{array}{c}\text { Highest } \\
\text { value }\end{array}$} & \multirow{2}{*}{$\begin{array}{c}\text { Range } \\
2.4\end{array}$} & \multirow{2}{*}{$\begin{array}{l}\text { Mean } \\
11.59\end{array}$} & \multirow{2}{*}{$\begin{array}{c}\begin{array}{r}\text { Standard } \\
\text { deviation }\end{array} \\
0.64\end{array}$} & \multirow{2}{*}{$\begin{array}{c}\text { Median } \\
11.8\end{array}$} & \multirow{2}{*}{$\begin{array}{c}\begin{array}{c}\text { Skewness } \\
\text { coefficient }\end{array} \\
0.98-\end{array}$} & \multirow{2}{*}{$\begin{array}{c}\begin{array}{c}\text { Coefficient } \\
\text { of } \\
\text { variations }\end{array} \\
5.54\end{array}$} \\
\hline \multirow{5}{*}{ Age } & $\begin{array}{l}\text { (1) year or } \\
\text { less }\end{array}$ & & & & & & & & \\
\hline & $\begin{array}{l}\text { From (1) to } \\
\text { (3) years }\end{array}$ & 12 & 14.2 & 2.2 & 13.34 & 0.85 & 13.5 & $0.57-$ & 6.34 \\
\hline & $\begin{array}{l}\text { From (3) to } \\
\text { (5) years }\end{array}$ & 14.4 & 16.9 & 2.5 & 15.41 & 0.65 & 15 & 1.90 & 4.19 \\
\hline & $\begin{array}{l}\text { From (5) to } \\
\text { (8) years }\end{array}$ & 16.5 & 18.8 & 2.3 & 17.81 & 0.61 & 18 & $0.92-$ & 3.42 \\
\hline & $\begin{array}{l}\text { more than } \\
(8) \text { years }\end{array}$ & 18.8 & 20 & 1.2 & 19.55 & 0.47 & 19.65 & $0.66-$ & 2.41 \\
\hline \multirow{5}{*}{ Height } & $\begin{array}{l}\text { (1) year or } \\
\text { less }\end{array}$ & 125 & 152 & 27 & 134.9 & 8.01 & 133 & 0.71 & 5.94 \\
\hline & $\begin{array}{l}\text { From (1) to } \\
\text { (3) years }\end{array}$ & 145 & 166 & 21 & 154.4 & 5.71 & 153.5 & 0.49 & 3.70 \\
\hline & $\begin{array}{c}\text { From (3) to } \\
\text { (5) years }\end{array}$ & 152 & 183 & 31 & 164.2 & 9.35 & 164 & 0.06 & 5.70 \\
\hline & $\begin{array}{l}\text { From (5) to } \\
\text { (8) years }\end{array}$ & 152 & 183 & 31 & 166.7 & 8.46 & 168 & $0.45-$ & 5.08 \\
\hline & $\begin{array}{l}\text { more than } \\
(8) \text { years }\end{array}$ & 156 & 185 & 29 & 173.2 & 7.86 & 171.5 & 0.67 & 4.54 \\
\hline \multirow{5}{*}{ Weight } & $\begin{array}{l}\text { (1) year or } \\
\text { less }\end{array}$ & 27 & 62 & 35 & 38.53 & 11.78 & 32 & 1.66 & 30.57 \\
\hline & $\begin{array}{l}\text { From (1) to } \\
\text { (3) years }\end{array}$ & 30 & 67 & 37 & 51.23 & 12.96 & 55 & $0.87-$ & 25.30 \\
\hline & $\begin{array}{c}\text { From (3) to } \\
(5) \text { years }\end{array}$ & 41 & 85 & 44 & 59.53 & 11.26 & 60 & $0.12-$ & 18.92 \\
\hline & $\begin{array}{l}\text { From (5) to } \\
\text { (8) years }\end{array}$ & 43 & 85 & 42 & 59.80 & 9.29 & 60 & 0.06- & 15.54 \\
\hline & $\begin{array}{l}\text { more than } \\
(8) \text { years }\end{array}$ & 43 & 67 & 24 & 60.27 & 6.37 & 62 & $0.82-$ & 10.57 \\
\hline
\end{tabular}

It is clear from Table (3) that skewness the research sample. Also, it shows a variance coefficient values of the key variables (age, between the research groups.

height and weight) by years of practice fell within $( \pm 3)$. This indicates the moderation of 


\section{Geographical Scope:}

The pilot study was conducted in Alexandria Weapon Club, while the basic study was conducted in a number of clubs in Cairo and Alexandria.

\section{Time Scope:}

The basic study was conducted in the period from $10 / 06 / 2010$ to $30 / 11 / 2010$.

\section{Measurements used in the research:}

\section{Posture Measurements:}

\section{Wry Neck}

Goniometer with Arms was used to measure the wry neck. Green Field, James and Gary,Tomas Lunsford, and Poul Esposito stressed the importance of the use of the Goniometer with Arms as a standardized detailed measurement of different parts of the body, measuring bone positions and angles in degrees from zero to 360 degrees clockwise and vice versa. Arms can be moved and fixed on the measured angular position. Size is taken in degrees . (5), (10:60), (24), (20). Ahmed Khater and Ali El-Beik suggest that measuring by degrees is relatively more accurtae, when compared to measuring by centimeters $(2: 380)$.

Three points were selected to measure deviation in the cervical areas: the most prominent point in the back of the head (Atlanto-occipital joint), where one arm of the Goniometer was placed; the spine of the fifth cervical vertebra (the deepest point in the cervical cavity), where the zero point of the Goniometry scale was placed and the spine of the seventh cervical vertebra (the most prominent point at the end of cervical cavity), where the other arm of the Goniometer was placed. The degree for this deviation was measured based on these points (23: 143) (17: 371).

\section{Low Shoulders}

The Goniometer with Arms was used to measure low shoulders. The zero point was placed on the spine of the seventh cervical vertebra (the most prominent point at the end of the cervical cavity), and the two arms of the Goniometer were placed on the Acromioclavicular joint. In this regard, Sobhy Hassanein and Mohammed Abdel-Salam state that the correct angle of the shoulders is 140 degrees. A wider angle would cause a hanging shoulder, and a narrower angle means low shoulders (16: 163).

\section{Scoliosis}

A scoliometer was used to measure the degree of scoliosis. It consists of a ruler with a graded protractor in the middle, a spirit level using the same protractor, two bars moving on a nut and another nut allowing the perpendicular bar to move up and down. To measure scoliosis in degrees, the individual to be measured stands in an upright position. The two bars are placed horizontally on the Acromioclavicular joint. The reading of the ball position is taken using the protractor scale. If the scale gives a degree higher than 2.5 , it will be recorded as positive (23:141), (22:504), (21: 101).

\section{Bow leggedness - genu varum}

In bow leggedness - genu varum, the lower limb curves out, when the feet are put together, and the distance between the two knees determine the degree of deformity (23:98). A centimeter measuring tape was used to measure the amount of the bow leggedness by putting the tape on the medial side of the knee joint.

\section{Morphological Measurements: \\ Height:}

Height was measuered to the nearest $0.5 \mathrm{~cm}$ by using an anthropometer. (14:27), (17: 51)

\section{Weight:}

Weight was measuered to the nearest $0.5 \mathrm{~kg}$ by using a calibrated medical balance (2: 94), (17: 56)

\section{The Basic Study:}

The basic study was conducted in the period from 10/06/2010 to 11/30/2010 in a number of Egyptian clubs in Cairo and Alexandria. Postural deviations were measured in foil fencers of different levels starting from less than a year of practice to over 8 years of practice.

\section{Statistical treatments:}

Mean - standard deviation - skweness coefficient - correlation coefficient

One Way analysis of variance (ANOVA)

Significance of differences using Tukey test Tukey \& HSD 
Multivariate analysis of covariance Presentation and Discussion of Results: (MANCOVA)

Table (4)

Statistical description of the search sample of foil fencers in wry neck, low shoulders, scoliosis and bow leggedness, resulting from years of practice

\begin{tabular}{|c|c|c|c|c|c|c|c|c|c|}
\hline Years of practice & 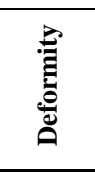 & 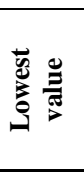 & 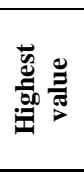 & 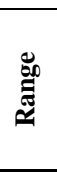 & $\stackrel{\Xi}{\Sigma}$ & 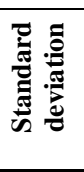 & 氞 & 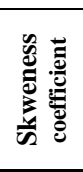 & 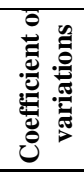 \\
\hline (1) year or less & \multirow{5}{*}{$\begin{array}{l}\frac{y}{0} \\
\stackrel{0}{\Xi} \\
\stackrel{2}{3}\end{array}$} & 0 & 2 & 2 & 0.63 & 0.61 & 1 & $1.79-$ & 97.10 \\
\hline From (1) to (3) years & & 1 & 3 & 2 & 2.27 & 0.74 & 2 & 1.08 & 32.63 \\
\hline From (3) to (5) years & & 1 & 6 & 5 & 3.10 & 1.42 & 3 & 0.21 & 45.89 \\
\hline From (5) to (8) years & & 3 & 6 & 3 & 4.23 & 1.04 & 4 & 0.67 & 24.57 \\
\hline more than $(8)$ years & & 3 & 6 & 3 & 4.67 & 1.27 & 5 & $0.79-$ & 27.18 \\
\hline (1) year or less & \multirow{5}{*}{ 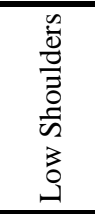 } & 125 & 144 & 19 & 130.90 & 3.90 & 131 & $0.08-$ & 2.98 \\
\hline From (1) to (3) years & & 124 & 145 & 21 & 132.73 & 3.88 & 133 & $0.21-$ & 2.92 \\
\hline From (3) to (5) years & & 125 & 138 & 13 & 132.97 & 4.59 & 134 & $0.68-$ & 3.45 \\
\hline From (5) to (8) years & & 134 & 139 & 5 & 136.50 & 1.63 & 136 & 0.92 & 1.20 \\
\hline more than $(8)$ years & & 130 & 145 & 15 & 137.90 & 3.64 & 138 & $0.08-$ & 2.64 \\
\hline (1) year or less & \multirow{5}{*}{$\begin{array}{l}\frac{n}{0} \\
\stackrel{0}{0} \\
0 \\
0\end{array}$} & 1 & 3 & 2 & 1.67 & 0.71 & 2 & $1.41-$ & 42.67 \\
\hline From (1) to (3) years & & 2 & 6 & 4 & 2.83 & 0.87 & 3 & $0.57-$ & 30.86 \\
\hline From (3) to (5) years & & 3 & 6 & 3 & 4.60 & 0.72 & 5 & $1.66-$ & 15.74 \\
\hline From (5) to (8) years & & 4 & 6 & 2 & 5.17 & 0.83 & 5 & 0.60 & 16.14 \\
\hline more than $(8)$ years & & 4 & 10 & 6 & 7.67 & 1.40 & 8 & $0.72-$ & 18.23 \\
\hline (1) year or less & \multirow{5}{*}{ 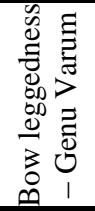 } & 0 & 6 & 6 & 4.13 & 2.15 & 5 & $1.21-$ & 51.90 \\
\hline From (1) to (3) years & & 5 & 6 & 1 & 5.33 & 0.48 & 5 & 2.09 & 8.99 \\
\hline From (3) to (5) years & & 4 & 10 & 6 & 6.20 & 1.81 & 5.5 & 1.16 & 29.16 \\
\hline From (5) to (8) years & & 3 & 10 & 7 & 6.27 & 1.95 & 6 & 0.41 & 31.06 \\
\hline more than $(8)$ years & & 6 & 10 & 4 & 8.33 & 1.27 & 8.5 & $0.39-$ & 15.22 \\
\hline
\end{tabular}

Table (4) shows that skweness coefficient values of wry neck, low shoulders, Scoliosis and bow leggedness - genu varum deformities fell within $( \pm 3)$, indicating the moderation of the sample. Also, it is evident from the values of means that there is a variance between foil fencers in all deformities, resulting from years of practice.

Table (5)

One way analysis of variance between years of practice of foil fencers in wry neck, low shoulders, scoliosis and bow leggedness - genu varum

\begin{tabular}{|c|c|c|c|c|c|}
\hline $\begin{array}{l}\text { Statistical } \\
\text { treatments }\end{array}$ & Source of variance & Freedom degree & Squares sum & Squares mean & (D) value \\
\hline \multirow{3}{*}{ wry neck } & Inter-groups & 4 & 313.37 & 78.34 & $* * 69.45$ \\
\hline & Intra -groups & 145 & 163.57 & 1.13 & \\
\hline & Total sum & 149 & 476.94 & & \\
\hline \multirow{3}{*}{ Low Shoulders } & Inter - groups & 4 & 1006.27 & 251.57 & $* * 18.71$ \\
\hline & Intra - groups & 145 & 1949.73 & 13.45 & \\
\hline & Total sum & 149 & 2956.00 & & \\
\hline \multirow{3}{*}{ Scoliosis } & Inter - groups & 4 & 636.71 & 159.18 & $* * 179.10$ \\
\hline & Intra - groups & 145 & 128.87 & 0.89 & \\
\hline & Total sum & 149 & 765.57 & & \\
\hline \multirow{3}{*}{ Bow leggedness } & Inter - groups & 4 & 284.11 & 71.03 & $* * 26.31$ \\
\hline & Intra - groups & 145 & 391.47 & 2.70 & \\
\hline & Total sum & 149 & 675.57 & & \\
\hline
\end{tabular}

$*$ Tabulated $(D)$ value at the level of $(0.05)=2.44 \quad *$ at the level of $0.01=3.47$ 
Table (5) shows that there are statistically significant differences between the years of practice of foil fencers at the level of 0.01 in the wry neck, low shoulders, scoliosis and bow leggedness - genu varum.

Table (6)

Significant differences between years of practice of foil fencers in wry neck, low shoulders, scoliosis and bow leggedness - genu varum using the Tuckey test (HSD)

\begin{tabular}{|c|c|c|c|c|c|c|c|c|}
\hline \multirow[b]{2}{*}{ 旁 } & \multirow[b]{2}{*}{ 苞 } & \multirow[b]{2}{*}{$\sum_{\Sigma}^{\tilde{E}}$} & \multicolumn{5}{|c|}{ Means differences } & \multirow[b]{2}{*}{ 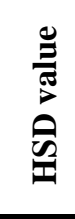 } \\
\hline & & & $\begin{array}{c}(1) \\
\text { year } \\
\text { or } \\
\text { less }\end{array}$ & $\begin{array}{c}\text { From (1) } \\
\text { to }(3) \\
\text { years }\end{array}$ & $\begin{array}{c}\text { From (3) } \\
\text { to }(5) \\
\text { years }\end{array}$ & $\begin{array}{c}\text { From }(5) \\
\text { to }(8) \\
\text { years }\end{array}$ & $\begin{array}{c}\text { more } \\
\text { than }(8) \\
\text { years }\end{array}$ & \\
\hline (1) year or less & \multirow{5}{*}{$\begin{array}{l}\text { 仓ै } \\
\stackrel{\Xi}{\Xi} \\
\stackrel{2}{3}\end{array}$} & 0.63 & & $* 1.64 \uparrow$ & $* 2.47 \uparrow$ & $* 3.60 \uparrow$ & $* 4.04 \uparrow$ & \multirow{5}{*}{0.47} \\
\hline From (1) to (3) years & & 2.27 & & & $* 0.83 \uparrow$ & $* 1.96 \uparrow$ & $* 2.40 \uparrow$ & \\
\hline From (3) to (5) years & & 3.10 & & & & $* 1.13 \uparrow$ & $* 1.57 \uparrow$ & \\
\hline From (5) to (8) years & & 4.23 & & & & & 0.44 & \\
\hline More than (8) years & & 4.67 & & & & & & \\
\hline (1) year or less & \multirow{5}{*}{$\begin{array}{l}0 \\
\frac{0}{0} \\
0 \\
0 \\
\frac{0}{2} \\
0 \\
3 \\
0 \\
0\end{array}$} & 130.90 & & $* 1.83 \uparrow$ & $* 2.07 \uparrow$ & $* 5.60 \uparrow$ & $* 7.00 \uparrow$ & \multirow{5}{*}{1.63} \\
\hline From (1) to (3) years & & 132.73 & & & 0.23 & $* 3.77 \uparrow$ & $* 5.17 \uparrow$ & \\
\hline From (3) to (5) years & & 132.97 & & & & $* 3.53 \uparrow$ & $* 4.93 \uparrow$ & \\
\hline From (5) to (8) years & & 136.50 & & & & & 1.40 & \\
\hline More than (8) years & & 137.90 & & & & & & \\
\hline (1) year or less & \multirow{5}{*}{$\begin{array}{l}\frac{n}{0} \\
.0 \\
0 \\
0 \\
\infty\end{array}$} & 1.67 & & $* 1.17 \uparrow$ & $* 2.93 \uparrow$ & $* 3.50 \uparrow$ & $* 6.00 \uparrow$ & \multirow{5}{*}{0.42} \\
\hline From (1) to (3) years & & 2.83 & & & $* 1.77 \uparrow$ & $* 2.33 \uparrow$ & $* 4.83 \uparrow$ & \\
\hline From (3) to (5) years & & 4.60 & & & & $* 0.57 \uparrow$ & $* 3.07 \uparrow$ & \\
\hline From (5) to (8) years & & 5.17 & & & & & $* 2.50 \uparrow$ & \\
\hline more than $(8)$ years & & 7.67 & & & & & & \\
\hline (1) year or less & \multirow{5}{*}{ 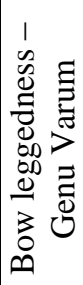 } & 4.13 & & $* 1.20 \uparrow$ & $* 2.07 \uparrow$ & $* 2.13 \uparrow$ & $* 4.20 \uparrow$ & \multirow{5}{*}{0.73} \\
\hline From (1) to (3) years & & 5.33 & & & $* 0.87 \uparrow$ & $* 0.93 \uparrow$ & $* 3.00 \uparrow$ & \\
\hline From (3) to (5) years & & 6.20 & & & & 0.07 & $* 2.13 \uparrow$ & \\
\hline From (5) to (8) years & & 6.27 & & & & & $* 2.07 \uparrow$ & \\
\hline more than $(8)$ years & & 8.33 & & & & & & \\
\hline
\end{tabular}

* significant at 0.05

Table (6) shows that there are significant shoulders, scoliosis and bow leggedness - genu differences at the level of 0.05 in wry neck, low varum as a result of years of practice. 
Table (7)

Multivariate Analysis of Covariance between research groups (years of practice) in wry neck, low shoulders, scoliosis and bow leggedness - genu varum deformities, isolating the effect of key variables (age, height and weight)

\begin{tabular}{|c|c|c|c|c|c|c|}
\hline Variance sources & & $\begin{array}{c}\text { Freedom } \\
\text { degree }\end{array}$ & $\begin{array}{l}\text { Squares } \\
\text { sum }\end{array}$ & $\begin{array}{l}\text { Squares } \\
\text { mean }\end{array}$ & $\begin{array}{c}\text { (D) } \\
\text { value }\end{array}$ & $\begin{array}{c}\text { Freedom } \\
\text { degree }\end{array}$ \\
\hline \multirow{4}{*}{ Age effect } & wry neck & 1 & 0.00 & 0.00 & 0.00 & 0.95 \\
\hline & low shoulders & 1 & 3.43 & 3.43 & 0.25 & 0.62 \\
\hline & scoliosis & 1 & 0.21 & 0.21 & 0.23 & 0.63 \\
\hline & $\begin{array}{c}\text { bow } \\
\text { leggedness }\end{array}$ & 1 & 2.62 & 2.62 & 1.00 & 0.32 \\
\hline \multirow{4}{*}{ Height effect } & wry neck & 1 & 0.73 & 0.73 & 0.64 & 0.43 \\
\hline & low shoulders & 1 & 1.13 & 1.13 & 0.08 & 0.77 \\
\hline & scoliosis & 1 & 0.09 & 0.09 & 0.10 & 0.75 \\
\hline & $\begin{array}{c}\text { bow } \\
\text { leggedness }\end{array}$ & 1 & 6.78 & 6.78 & 2.59 & 0.11 \\
\hline \multirow{4}{*}{ Weight effect } & wry neck & 1 & 0.41 & 0.41 & 0.36 & 0.55 \\
\hline & low shoulders & 1 & 0.12 & 0.12 & 0.01 & 0.92 \\
\hline & scoliosis & 1 & 0.98 & 0.98 & 1.09 & 0.30 \\
\hline & $\begin{array}{c}\text { bow } \\
\text { leggedness }\end{array}$ & 1 & 14.73 & 14.73 & $* 5.62$ & 0.02 \\
\hline \multirow{4}{*}{$\begin{array}{c}\text { Groups effects (years of } \\
\text { practice) }\end{array}$} & wry neck & 4 & 13.98 & 3.50 & $* 3.06$ & 0.02 \\
\hline & low shoulders & 4 & 112.44 & 28.11 & $* 3.05$ & 0.02 \\
\hline & Scoliosis & 4 & 53.95 & 13.49 & $* * 15.06$ & 0.00 \\
\hline & $\begin{array}{c}\text { bow } \\
\text { leggedness }\end{array}$ & 4 & 53.97 & 13.49 & $* * 5.15$ & 0.00 \\
\hline \multirow{4}{*}{ Intra - group (error) } & wry neck & 142 & 162.25 & 1.14 & & \\
\hline & low shoulders & 142 & 1944.79 & 13.70 & & \\
\hline & scoliosis & 142 & 127.20 & 0.90 & & \\
\hline & $\begin{array}{c}\text { bow } \\
\text { leggedness }\end{array}$ & 142 & 372.29 & 2.62 & & \\
\hline \multirow{4}{*}{ Total sum } & wry neck & 149 & 476.94 & & & \\
\hline & low shoulders & 149 & 2956.00 & & & \\
\hline & scoliosis & 149 & 765.57 & & & \\
\hline & $\begin{array}{c}\text { bow } \\
\text { leggedness }\end{array}$ & 149 & 675.57 & & & \\
\hline
\end{tabular}

Table (7) shows that there are no statistically significant effects of key variables (age, height and weight) on the wry neck, low shoulders, scoliosis, bow leggedness - genu varum deformities except for the effect of weight on the bow leggedness - genu varum, where the calculated D value was $5.62 *$ which was significant at a level of 0.05 . Also, it is evident that the number of years of practice have an effect on wry neck, low shoulders, scoliosis, bow leggedness - genu varum) deformities. 
Table (8)

Matrix of correlation coefficient between (wry neck, low shoulders, Scoliosis and Bow leggedness - genu varum) deformities to foil fencers under study

\begin{tabular}{|c|c|c|c|c|}
\hline & Wry neck & Low shoulders & Scoliosis & Bow leggedness \\
\hline Wry neck & & $* * 0.43$ & $* * 0.70$ & $* * 0.50$ \\
\hline Low shoulders & & & $* * 0.52$ & $* * 0.29$ \\
\hline Scoliosis & & & & $* * 0.56$ \\
\hline Bow leggedness & & & & \\
\hline
\end{tabular}

Tabular $R$ value at the level of $0.05=0.17 *$

level $0.01=0.23 * *$

Table (8) shows that there are statistically significant direct correlation coefficients between wry neck, low shoulders, scoliosis,

Figure (1)

The arithmetic mean for foil fencers in wry neck as a result of years of practice

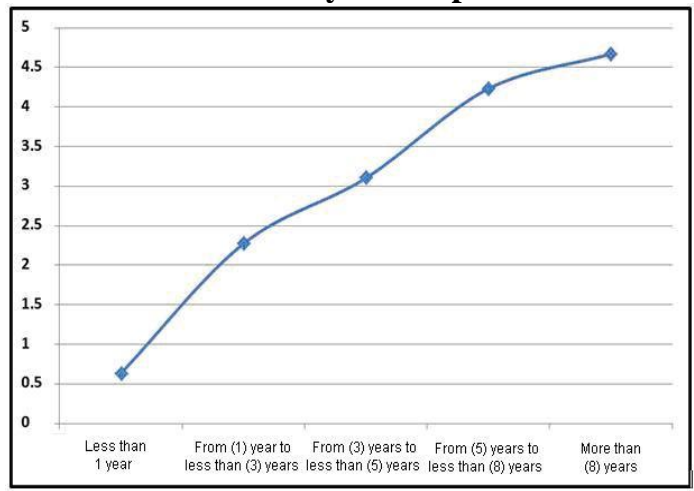

Figure (3)

The arithmetic mean for foil fencers in scoliosis, resulting from years of practice

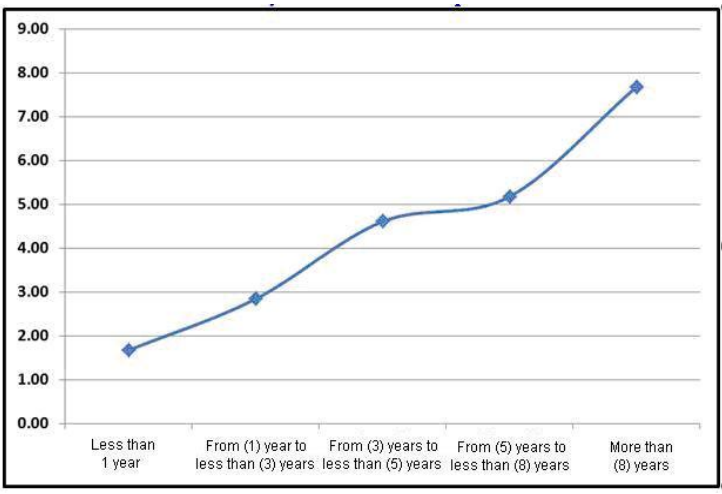

Table (4) (Statistical description of the search sample of foil fencers in wry neck, low shoulders, scoliosis and bow leggedness, resulting from years of practice) shows that skweness coefficient values of wry neck, low shoulders, scoliosis and bow leggedness - genu varum deformities fell within $( \pm 3)$, indicating the moderation of the sample. Also, it is evident from the values of means that there is a variance bow leggedness - genu varum deformities in foil fencers.

Figure (2)

The arithmetic mean for foil fencers in low shoulders, resulting from years of practice

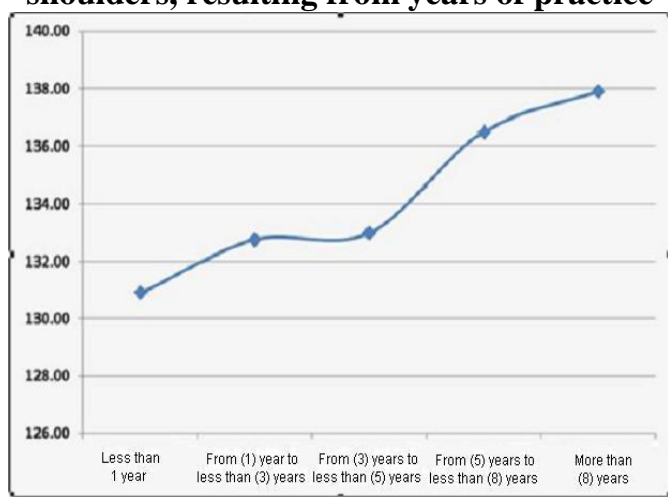

Figure (4)

The arithmetic mean for foil fencers in bow leggedness - genu varum, resulting from years of practice

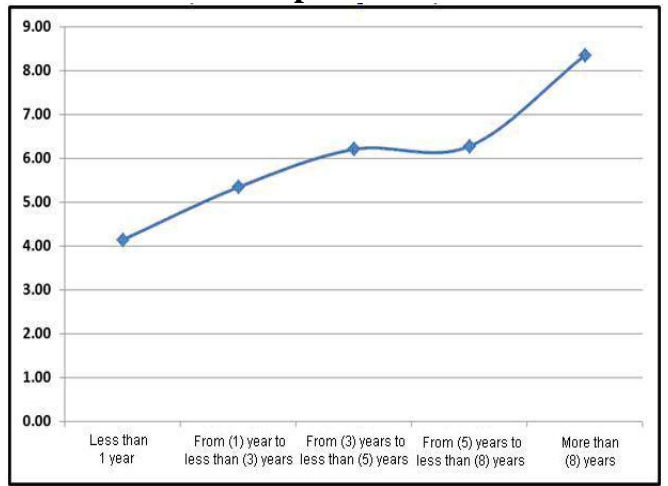

between foil fencers in all deformities. The table also shows the following values:

- the wry neck deformity: the lowest value fell between 0 and 3 , and the highest value fell between 2 and 6 ;

- the low shoulders deformity: the lowest value fell between 125- and 130, and the highest value fell between 144 and 145 ; 
- The scoliosis deformity: the lowest value fell between 1 and 4 and the highest value fell between 3 and 10;

- The bow leggedness deformity: the lowest value fell between 0 and 6 and the highest value fell between 6 and 10 .

The above values are all statistically significant starting from a practicing period of less than a year to a period longer than 8 years. This is attributed to the absence of the scientific method in all training stages beginning with the stage of the selecting the beginners. This is evident from the results of the first stage where the period of practice does not allow the emergence of deformities. Rather, it can be traced back to poor selection of beginners at this initial important stage.

Figures (1), (2), (3) and (4) represent the arithmetic means of the deformities studied. Except for the low shoulders deformity, the degrees of deformities increase as a result of practicing. In low shoulder deformities, the degree of deformity was closer to the correct angle as defined by several experts, which is 140 degrees. A lower degree would lead to low shoulders (16:101). The rest of deformities, on the contrary, show an increase in degree due to bad practices in training that would increase the degree of deformity, and do not allow the opposite muscles to be equivalent in strength to the muscles used during training. Facing the opponent by side throughout the duel and repeating the performance for long periods of training lead to deformities as a result of training in a wrong manner and neglecting the muscles on the opposite side of the body.

Table (5) ( One way analysis of variance between years of practice of foil fencers in wry neck, low shoulders, scoliosis and bow leggedness - genu varum) shows that there are statistically significant differences between the years of practice of foil fencers in the deformities studied. The calculated D value was higher than the tabular $\mathrm{D}$ value in all stages studied.

Postural deviations resulting from practicing for years can be attributed to the fact that foil fencers keep on using one side of the body as an inevitable performance requirement of this particular sport. This leads to a state of muscle imbalance so that the leading arm side gets stronger, while the free arm side gets weaker. With fast repetition of footwork, and attack and defense movements repeated, always in one direction, deformities occur especially with regular training. With the influence of gravity, the muscle tone is weakened and the muscular imbalance on both sides of the spine causes the body to arch towards the stronger muscles, leading to the so-called scoliosis (17: 64) (23:36). Fencing and fencing on horseback require repeated performance of standing en garde, which in turn affects the spine and leads to feet deformities, especially bow leggedness (23:100) (1:206). (7:30). Facing the opponent by side, and turning the head towards him/her leads to a muscle contraction vs. a muscle relaxation on the other side, wearing the protective head guard, leads to wry neck deformities. Turning the head and contracting it in the desired direction lead to a straining of the muscle groups working on the limbs on this side and creates a state of imbalance in the muscle tone, shortening one of the muscles moving the neck to both sides, causing the wry neck deformity $(17: 102)(23: 36)$. Career habits that use one side of the body may cause one shoulder to rise compared to the other, thus causing the low shoulders deviation (16:162). Experts agree that foil fencing is an individual sport which requires a performance different from that required by other individual sports. The en garde position taken during long periods of training through all the stages of learning footwork, attacks and defense movements, in order to face the opponent, affect the efficiency of the work of muscles and bones, thus strengthening the side of the body used in the movement, detrimental to the other side, causing some posture deviations. On the contrary, foil fencing can be used for the treatment of some postural deformities such as round shoulders and low shoulders deformities (8:30), (19:45), (1 :150), (16:102). This is consistent with this study, as the low shoulders deformity came closer to the degree of measurement in the stages of practice from 5-8 years, and from 3-5 years to the correct angle which is 140 degrees, as a result of regular practicing of the sport of foil fencing.

Table (6) (Significant differences between years of practice of foil fencers in wry neck, low 
shoulders, scoliosis and bow leggedness - genu deformities) shows that all the deformities increase as a result of practicing, starting from the first stage of less than 1 year to the stage of more than 8 years, except for the low shoulders deformities. As a result of practicing, the measurement of the deformity degree has increased. Unlike other studies which suggest the presence of this deformity in foil fencers. Yet, when measuring the deformity by degree, this study found that the deformity degree ranged from 125 to 139 degrees, i.e., it was closer to the correct angle. Only this amount of deformity came as a result of practicing. The rest of the deformities were attributed by authors of this present study to the lack of training programs conducted by experts, and based on science. Such training programs would enable the coach to focus on giving a compensatory training to address the effects of continuous training for long periods, which can last up to several hours continuously during massed championships and continue for days thus becoming a major cause of posture deformities in foil fencers.

This is consistent with table (7) (Multivariate Analysis of Covariance between research groups (years of practice) in wry neck, low shoulders, scoliosis and bow leggedness - genu varum deformities, isolating the effect of key variables (age, height and weight) reflects the absence of any effects of statistical significance of the key variables (length - Age - Weight) on the said deformities, except for the effect of weight on the bow leggedness - genu varum. Hence, gaining weight can affect the lower limbs as a result of carrying the body weight during walking and running, where knees are wide apart in the standing position and feet put together, causing bthe knees to bend. This is more common in boys than girls (16:101). It is clear from the table that the number of years of practice has an effect on the wry neck, low shoulders, scoliosis and bow leggedness - genu varum deformities. The repetition of performing the skills by one side, whether the right or the left side, and doing this continuously for a long training period result in muscle imbalance as well as muscular incompatibility of the two sides $(15: 16)(18: 30)$.
Table (8) (Matrix of correlation coefficient between (wry neck, low shoulders, Scoliosis and Bow leggedness - genu varum) deformities to foil fencers) shows that there are direct correlation coefficients of statistical significance between wry neck, low shoulders, scoliosis and ow leggedness - genu varum deformities in foil fencers. This is attributed to the directly proportional effect of any deviation on some other deviation. Wry neck leads to low shoulders. When one shoulder is higher than the other, this leads to scoliosis. Therefore, Sobhy Hassanein and Mohammed Abdel-Salam indicate that the presence of any deformity reduces the efficiency of the joints and the muscles working in the area of deformity, both on functional or mechanical levels. They also suggest that the presence of postural deviations in the body changes its mechanism when performing different skills and divert forces into other tracks that do not serve the same skill (16: 35-37).

\section{Conclusions:}

1. Years of practice have a significant effect on the degree of wry neck deformities, scoliosis and bow leggedness - genu varum.

2. Practicing foil fencing causes the measured degree of the low shoulders deformity to come closer to the correct degree which is 140 degrees, thus improving the deformity.

3. There is a direct correlation between the degree of deformities of wry neck, scoliosis and low shoulders and years of practice.

4. Gaining weight leads to bow leggedness deformities.

\section{Recommendations:}

1. Posture measurements should be taken and medical examination should be conducted when selecting foil fencing beginners, so that the selection is based on scientific rules.

2. Foil fencing coaches should be made aware of the need for training fencers in a scientific manner so that practitioners can be protected against postural deviations which are on the rise increasing according to results of this study. While due care is given to the working muscles, 
other muscles should not be neglected in training all through the years of training.

3. Studies similar to this study should be made on the three other types of fencing and also on other sporting activities in general.

\section{References:}

1. Abbas Abdel-Fattah Al-ramly: Weapon Foil fencing, Cairo, Dar Al-fikr El-Arabi 1993.

2. Ahmed Mohammed Khater, Ali Fahmy Albek: Measurement in the sports field, Dar Elkitab Al-hadith, fourth edition, 1996.

3. Alexander, H 2005: What is Foil fencing? www.usfa.foil fencing

4. Bower, M. 1990: Foil Foil fencing, 6th, ed, Wmc. Brown Publishers, Printed in the united states of America.

5. Geenfield, JA: Two New Geniometer Knee and Elbow Otheroses, http://www.uhsl.comp/gomhtml

6. Hayat Ayyad Roviaúal, Safa Safa al-Din Alkhrbutaly: Posture Fitness and sports massage, Monchaat Al-Maaref, Alexandria, 1995.

7-Hussain Ahmed Haggag \& Ramzi Abdul Qadir Al-Tanpole: Weapon Foil fencing "skills Explanation of some articles of the law," El-fath for printing and publishing, Alexandria,2004.

8.

: Science and art of

foil fencing "basic skills - explanation of the articles of the law," El-fath for printing and publishing, Alexandria. 2005.

9. Ibrahim Nabil Abdul Aziz Murad: Posture deformities of Weapon players in ArabRepublic of Egypt, Unpublished Master Thesis, Faculty of Physical Education, HelwanUniversity, 1973.

10. James, RA, Gary, LH: Physical Rehabilitation of Injured Athlete, 1st, UB Saunders Company, Philadelphia, 1991.

11. Mahrosa Ali Hassan, Mervat El-said Yousef: Identifying posture deviations of female foil fencers and basketball players, Research published in the Faculty of Physical Education for Girls, AlexandriaUniversity, No.6, 1994.

12. Metzing, Miklos.: Basics of Exercises and Sport, Conditioning Budapest, Physical Education, Hungary 1996.

13. Miller, DK: Measurement by the Physical Educator, 3ed, WCB McGraw-Hill Co., Boston, 1998.
14. Mohammed Ibrahim Shehata, Mohammed Jaber Briqa': A Guide of physical measurements and motor performance tests, Monchaat AlMaaref, 1995.

15. Mohammad Reda Hafez Al-Rouby: Teaching Encyclopedia of Romanian Wrestling, first edition, Mahy for publication and distribution, 2008.

16. Mohammed Sobhy Hassanein, Mohammed Abdel-Salam Ragheb: proper posture for all, Dar El-fekr El-Arabi, 2003.

17. Mohammed Sobhy Hassanein: Measurement and Evaluation in Physical and Sports Education, Part II, fourth edition, Dar Al-fikr El-Arabi, 2000.

18. Mossad Ali Mahmoud, Mohammed Reda Al-Rouby, Hassan Abdel-Salam Mahfouz: The theoretical and applied basis of the Romanian wrestling and free wrestling, fifth edition, Dar Al-fikr El-Arabi, 2001.

19. Osama Ahmed Ismail: A proposed treatment program for orthopedic of the backbone deviations of foil fencing players, Unpublished Master Thesis, Faculty of Physical Education for Girls, HelwanUniversity 1999.

20. Paul Esposito, MD: Pediatriv Orthopadics, http://www.unmc.Edu/Pediatrics/M31ectures/ha n douts / ortho.htm, 1999.

21. Roger.E, Thomas.R: Kinanthropometry And Exercises Physiology Laboratory Manual, 1st, E \& FN spon, London 1996.

22. Sabia's: Handbook of Instruction, 30 N.Prospecl Avenue, Red Bank, N do 7702.

23. Safa Safa al-Din Alkhrbutaly: Posture Fitness and Massage, Dar El-gam'een for printing and binding, Alexandria, 2011.

24. Thomas, R., Lunsford, A.: Tools for Evaluating the Physiotheraphy and theOccupational, Goniometer with Arms, http://www.plastidb.It/UK/strumenti medici.htm 25. Wael Mohammed Ibrahim Omar: Identifying Posture Deviations of some sports activities players, Unpublished Master Thesis, Faculty of Physical Education for Boys, AlexandriaUniversity, 1993.

26. Zakaria Ahmed El-said Metwally: The impact of a program of therapeutic exercises and massage on the Scoliosis deviation for pupils from 9-12 years, Unpublished Master Thesis, Faculty of Physical Education for Boys, Alexandria University, 2001. 
